\title{
Discussion on the Applicability of the Method of Carbon Emission Evaluation
}

\author{
Yuan Xiu'e \\ Department of Economics and Management \\ North China Electric Power University \\ Baoding, China
}

\author{
Wang Chenli, Cao Yang \\ Department of Economics and Management \\ North China Electric Power University \\ Baoding, China
}

\begin{abstract}
The purpose of this paper is to study the assessment method of carbon emission value. Firstly I introduce the traditional evaluation methods in the process, which are market method, income method and cost method. Then I analyze the applicability of those methods by combining the carbon emission value. As a result, these methods all have some limitations. So I propose a new method-evaluation model of gray system theory. The innovation of this paper lies in proposing a more suitable method to evaluate the carbon emission value.
\end{abstract}

Keywords - carbon emissions; market method; income method; cost method; evaluation

\section{INTRODUCTION}

\section{A. Economic Connotation of Carbon Emission Rights}

Carbon emissions trading is taking carbon emissions as a commodity, and taking their integration into an economic means of market mechanisms, which is a kind of property transaction. The origin, development and application of carbon emissions trading reflect the characteristics of property transactions. Carbon emissions trading are different from the environmental property rights among different owners. It is a carbon-trading emission rights ${ }^{[1]}$.

We can analyze the nature property of carbon emission rights from two sides. First, the carbon emissions are a series of bundle of rights. Including emissions trading and emission rights trading, carbon emissions involves ownership, use rights, the right to trade and usufruct. Second, carbon emissions reflect the ownership objectively, which reflects the rights and interests between economic agents. Two processes of carbon emissions trading are these: firstly, the government agency decides the attribution of carbon emissions, usually by the way of a license for free or auctioning to companies to be discharged, which is the initial configuration. Secondly, carbon emission rights exchange between microeconomic enterprises, accompanied by the right to dominion and gain emission rights corresponding transferred between companies.

\section{B. Finance Connotation of Carbon Emissions}

Carbon emissions refer to carbon rights, which is a new environment for financial products. Carbon emission rights itself has a home assignment and the actual use, but it did not occur in the current characteristics, which is to say carbon rights has the characteristics of financial derivatives. In addition, carbon emissions is a general reference, containing various forms of transactions in the carbon market, such as
CERs, EUAs and VERs and so can be called as a carbon emission rights. Carbon emissions of different types in different markets exhibit characteristics of different financial derivatives.

\section{SELECTED BASES OF CARBON EMISSION VALUATION METHODS}

\section{A. The asset nature of carbon emissions}

Since the carbon emissions trading system has been established, carbon emission rights have become a valuable resource which can be measured. From the perspective of asset evaluation, assets are owned or controlled by the specific subject of rights and economic resources which can bring future economic benefits to the specific subject of rights. Carbon emissions have assets property, embodied in the following two aspects:

First, the specific subject of rights can be owned or controlled. When in the primary market, carbon credits are issued subjects to be controlled by the quota or certified on the primary market, these main body are cooperation of policy or environmental agreements such as the EU and national governments. When in the secondary market, as an establishment of the carbon emissions trading, carbon emission owned by companies has the right to dispose their property. Companies will seek to gain their favorite use of carbon credits. Second, the economic resources can bring future economic benefits to the specific subject of rights. In the primary market, the government allocates carbon emission rights, effectively allocating resources and reducing external diseconomies. To some extent, the carbon emissions are scarce, for those who benefit from the control or at least improve the environment. In the secondary market, companies are in the completion of their emission reduction targets. In the same time, companies transfer the carbon emission to the unfinished business, so as to help them not only complete reduction but also gain economic benefits. According to the above two features, we believe that carbon emissions have to assess the nature of the assets in the asset $^{[2]}$

"Asset assessment criteria - Intangible Assets" points that intangible assets are the specific subjects which can be owned or controlled, which do not have the physical form and can continue to play a role in which resources can bring economic benefits. This paper argues that carbon emission rights belong to the intangible assets for the following reasons: 
First, non-entity. Carbon emission is a right, not a physical form, but it has value. The value of carbon emissions mainly reflects its enable enterprises to obtain the rights to emit greenhouse gases, and to use the resource and environmental capacity to produce the relevant product or provide a corresponding service, the part of the property is clear by allowing companies access to economic resources. Second, after the company has had sufficient resources capacity of the environment, it can sell excess carbon credits and transfer carbon emissions in the carbon trading market and get the appropriate economic benefits. The more carbon emissions enterprise has, the more room for development, the more economic benefits companies can get.

Second, the income is uncertain. First, if the energy structure changes, such as the increase in low-carbon energy, carbon emissions and business demand for carbon emissions will be reduced. Then the carbon emissions would reduce the value of the enterprise. So income will also be reduced. Secondly, the carbon emissions price in the carbon trading market has a large fluctuation. When companies sell carbon emission, the economic benefit is also full of uncertainties. So companies owned carbon emissions should grasp the price fluctuations and decide whether or when to sell carbon emissions. Therefore, carbon emissions are in line with the characteristics of intangible assets.

\section{B. Value Characteristics of Carbon Emission}

First, the environment is a scarce resource, and it will become more and scarcer. The carbon emission is a kind of right using the scarce resource capacity of the environment. Therefore carbon emissions also show scarcity, which will become scarcer with scarce environmental resources. Scarcity of carbon emissions may make carbon emission prices vulnerable to climate change, because of which the government introduces the relevant climate and environmental policies ${ }^{[3]}$.

Second, carbon emissions have product attributes and properties of quasi-property rights, which is a special kind of assets that can be traded on the market, having tradability. Currently, carbon emission trading has become an effective market-based instrument to response to climate change, alleviate the greenhouse effect, and promote energy conservation and low-carbon development. The carbon emission trading can make it as the general commodities. Its price is affected by a number of markets which supply and demand factors. Carbon emissions do not belong to the asset which can provide a fixed or determinable amount of money. With the stage nature, the holding period is generally longer. Therefore the expected economic benefit of carbon emission to the enterprise's future is uncertain.

Third, carbon emission rights are approval by the relevant authorities. Then governments distribute to each reduction body in a certain way, allowing its right or license to emit a certain amount of carbon dioxide within a certain time. In the transaction, with the transfer of ownership of carbon emission, the rights of the amount of emission will be transferred. Thus carbon emission has certain rights in property. Rights of carbon emission may make the price of carbon emissions be affected by the government quota distribution plan, number of distribution and way of distribution and other factors.

\section{APPLICABILITY OF VALUATION METHODS BASED ON CARBON EMISSIONS}

Carbon emission rights is a valuable asset that can be exchanged as a commodity on the market - - a difficult reduction company can buy carbon emission rights to easy reduction of the enterprise not only complete the task of reducing emissions for the former, but also gain benefit. Essentially value of carbon emissions is a kind of environmental property. The value is affected by regional emission stage arrangements, market and technological maturity in which emission credits and fulfills the agreements. This paper evaluates the value of the transaction as an asset when the carbon emission is in trading. $\square$ :

\section{A. Market Method}

Market method is a method that using the same price on the market or recent transactions of similar assets through direct comparison or analogy analysis to estimate the value of the assets by the various methods of assessment techniques in general. Market approach is based on the principle of substitution, using comparative methods and ideas and analogies to assess asset value.

When using market method to valuate assets, we need to meet two basic preconditions: to have an active public market; on the open market have comparable assets and trading activities. Open market is a developed market, in which the voluntary market buyers and sellers exist and conduct transactions equally. Market prices basically reflect market conditions. Estimating assets according to market value is closer to the market, which can be more likely to be acceptable to all asset transactions. Assets and comparable transactions which refer to select comparable assets and trading activity have taken place on the open market before the near future with the same or similar assessment of the assets and business assets. These assets which have been completed transaction can be evaluated as a reference asset, the transaction data is the main basis for comparative analysis.

Applicability analysis: Market method is the most direct and convincing in asset evaluation, but there are some limitations in the valuation of carbon emissions. Firstly, the carbon trading market has not been fully established. In China, the low-carbon construction started late. The current carbon emissions trading are still in the implementation stage. In recent years, carbon emissions trading market have been established in Beijing, Shanghai, Hubei and other provinces. The transaction trading case is relatively few. China is to take a quota of government-lead carbon emissions trading market at this stage. Carbon emission trading market is not entirely free and is still not mature. Secondly, the comparable index is less. Currently only 8 environment transactions involve carbon emissions trading and reference cases that can be provided relatively rare. Therefore, if we use a market method to assess the value of carbon emissions, there is no active market as a foundation. The operation is not only inconvenient; the reference value is also greatly reduced. However, China will start the national carbon trading market in 2017, with the increasingly sophisticated market. The market approach would be a direct way to assess the carbon emission rights. 
difficult to determine. It's not easy to determine the venture held by carbon emissions if we take a different discount rate when evaluating for each company. On one hand, the workload is too heavy; on the other hand, it is too subjective, contrary to the objective assessment principle. Therefore, income method does not apply to valuation of carbon emission rights.

\section{Cost Method}

Cost method is estimating the replacement cost of evaluated assets firstly, and then estimating the depreciation of the various factors, and is deducted from the replacement cost to obtain the value. The basic idea is to rebuild the cost method or reset the assessment of assets. Under the permit conditions, any potential investors when deciding to invest in an asset are willing to pay no more than the preceding construct the asset purchase completed to. If investments are not totally new, the price that investor would pay will be deducted from depreciation of various factors in the completion of the purchase of new capital investment object ${ }^{[3]}$.

Under normal circumstances, when evaluating objects are missing in the market data, the use of market method and income method is difficult to evaluate, while cost method can obtain information more easily. Therefore, we can choose the cost method as an alternative method, applied to the corresponding asset valuation practice. As a new trading pattern and available market data for reference, the carbon emissions trading are few, so cost method can be selected relatively feasible for research methods.

Applicability analysis: Cost method is an integral part of the assessment methods in the evaluation of intangible assets filed. On our carbon emissions trading market in China, particularly within the same industry, companies save carbon emissions mostly rely on energy conservation, the introduction of cleaning equipment, update management and other methods to achieve. In an open market environment, companies are willing to buy carbon credits rather than their own energy conservation. Thus, we can predict the carbon trading price lower than the cost of certain of its consumption. In order to achieve the right way to reduce carbon emissions consumption costs as the starting point, analyzing the potential impact way and discussing the carbon emission valuation is feasible ${ }^{[7]}$.

\section{ATtEMPT OF CONSTRUCTING GREy SySTEM MODEL}

Through the analysis, the traditional assessment methods to assess the value of carbon emissions have some deficiencies which the assessment results will be biased. So this paper proposes a new evaluation method, the gray system model. Application of the principle of gray system model is based on "partial information is known, some information is unknown," According to the less data and uncertain poor information system, gray system method is to generate part of the information known information for proper understanding of things.

Enterprises in assessing the value of carbon emissions are often faced with many complex issues in carbon emissions during their own scale. Investment and ways of reducing emissions will affect the value of carbon emission. In addition, there are many external factors; therefore it requires us to find the right approach to measure these factors index reasonably. 
On the one hand, factors that affect the value of carbon emission rights are inherently uncertain, and therefore carbon emission rights constitute a valuation of uncertain systems. On the other hand, the impact of enterprise data and external data can be obtained using the method of gray system which data have been generated notification information, model-based assessment of the value of carbon emission to make the assessment more comprehensive and reasonable. Thus, this paper intends to use the cost method to determine the carbon emissions of enterprises as the basis of valuation, then using gray system to a further analysis for impact factors, in order to have a certain reference on carbon emission valuation field.

\section{V.CONCLUSION}

In this paper, I describe three basic method of the assessment of carbon emission value-market method, income method and cost method. After analyzing the applicability, the market method and income method have some limitations, which can't apply to evaluation accurately. So we can use the cost method as the basic method, and then put forward a new method to construct the gray system model, which is an innovation in assessment methods.

\section{REFERENCES}

[1] Liu Xiaoxiao, "Factors carbon emissions price analysis," Hangzhou University of Electronic Science and Technology, 2015.

[2] Zhang Zhihong, Study, Qi Jie, ““Asset View’ carbon emission rights under the asset valuation perspective,” Economy and Management Review, 2015 (5): 58-65.

[3] Shawn Ho, "Firm-Value Effects of Carbon Emissions and Carbon Disclosures,” Accounting Review,2014,89(2):695-724.

[4] Duan Kang, "Carbon emissions based on the value of the replacement cost method,” Lanzhou University of Finance and Economics, 2015..

[5] John Downie, Wendy Stubbs, "Corporate Carbon Strategies and Greenhouse Gas Emission Assessments: The Implications of Scope 3 Emission Factor Selection,” Bus. Strat. Env. 2012, 216.

[6] Zhang Lijun, "Option pricing model in carbon emissions assessment ," Beijing Jiaotong University, 2015.

[7] Fu Yunhan, "Power generation companies based on a comprehensive evaluation method and carbon emission rights Evaluation of Value," 2015. 